Gut, 1982, 23, 215-220

\title{
Clinical detection of the hepatic lesion of pericentral sclerosis in chronic alcoholics
}

\author{
Y KAKU, Y HASUMURA, AND J TAKEUCHI* \\ From The Second Department of Internal Medicine, School of Medicine, Tokyo Medical and Dental \\ University, Tokyo, Japan
}

SUMMARY It has been shown that a specific liver lesion-that is, pericentral sclerosis associated with pericellular fibrosis-is the precursor of alcoholic liver sclerosis. It is, however, difficult to diagnose this hepatic lesion in chronic alcoholics, using only clinical data without liver biopsy. To investigate the possibility of a clinical test reflecting the presence of this hepatic lesion, ethanol $(0.75$ $\mathrm{g} / \mathrm{kg}$ body weight) was given orally to chronic alcoholics, and serum glycoprotein levels (prealbumin, $\alpha$ HSglycoprotein, haptoglobin, $\alpha_{2}$ macroglobulin) were measured before and six hours after. Chronic alcoholics were divided into three groups according to the histological findings in the liver at the time of study. Group I (alcoholic fatty liver or non-specific change) consisted of seven cases without pericentral sclerosis. Group II (alcoholic hepatic fibrosis or alcoholic hepatitis) consisted of five cases with pericentral sclerosis and pericellular fibrosis. Group III consisted of five cases with alcoholic liver cirrhosis. After the ethanol administration, serum glycoprotein levels decreased significantly in group I ( $\mathrm{P}<0.05)$, whereas they increased in group II and group III. Their alternative ratios ( see text) apparently differed $(\mathrm{P}<0.005)$ between group I and group II, and between group I and group III. These results indicate that the determination of serum glycoprotein levels before and after oral ethanol administration is a useful way of discriminating alcoholic patients with hepatic pericentral sclerosis and pericellular fibrosis from alcoholics without such lesions.

Alcoholic liver disease is increasing in proportion to the increase in alcohol consumption, and is becoming a serious health problem in Japan. ${ }^{1}$ It is therefore important to be able to diagnose and estimate the severity and prognosis of alcoholic liver disease.

Histological studies play an essential role in diagnosis and estimation of the severity of liver disease. It has been reported that a specific liver lesion-namely, pericentral sclerosis associated with pericellular fibrosis-is the precursor of alcoholic liver cirrhosis. ${ }^{2}$ It is, however, difficult to recognise this lesion in chronic alcoholics, if one uses only clinical data without liver biopsy. We therefore wanted to find some clinical marker indicating the presence of this hepatic lesion.

Hepatomegaly in alcoholics is reported to be attributable to protein deposition ${ }^{3}$ as well as fatty accumulation in the hepatocyte. ${ }^{4}$ It has been also suggested that this intracellular protein deposition is partly due to im-

* Address for reprint requests: Professor J Takeuchi, The Second Department of Internal Medicine, Tokyo Medical and Dental University, 1-5-45 Yushima, Bunkyo-ku, Tokyo 113, Japan.

Received for publication 14 September 1981 paired glycoprotein secretion from the hepatocyte, ${ }^{56}$ and that it might play a role in the pathogenesis of alcoholic liver disease.

We examined serum glycoprotein level changes after the acute administration of ethanol, as the serum glycoprotein levels might reflect an altered protein metabolism in the hepatocyte.

\section{Methods}

SUBJECT

Seventeen male patients were studied who had a history of heavy drinking (more than $100 \mathrm{~g}$ ethanol per day) for more than 10 years. Those who had a history of blood transfusion, a definite history of acute viral hepatitis, or a history of habitual taking of drugs were excluded from this study. None of them had HBs-Ag nor anti$\mathrm{HBs}$, as examined by radio-immunoassay, in their sera.

Under peritoneoscopic observation, liver biopsy, using a Vim Silverman needle, was performed. Liver specimens were interpreted independently by two observers without knowledge of clinical or laboratory data. Sections stained with haematoxylin and eosin, 
and trichrome-stained, were classified into the following categories, based on the histological findings specific to alcoholic liver injury. They consisted of (1) non-specific change, (2) fatty liver, (3) alcoholic hepatitis, (4) hepatic fibrosis, and (5) liver cirrhosis. The histological features are shown in Table 1.

Table 1 Histological classification of alcoholic liver disease

\begin{tabular}{ll}
\hline Classification & Histological features \\
\hline $\begin{array}{l}\text { Non-specific } \\
\text { change } \\
\text { of the liver }\end{array}$ & $\begin{array}{l}\text { Normal liver histology or non-specific } \\
\text { change of the liver }\end{array}$ \\
Fatty liver & $\begin{array}{l}\text { Fatty metamorphosis is recognised in } \\
\text { more than 25\% of specimen with little } \\
\text { other change }\end{array}$ \\
Alcoholic hepatitis & $\begin{array}{l}\text { Existence of following three findings } \\
\text { with few other findings: (1) hepatocyte } \\
\text { necrosis with polymorphonuclear } \\
\text { leucocyte infiltration with or without } \\
\text { Mallory bodies, (2) fatty accumu- } \\
\text { lation, (3) pericentral sclerosis with } \\
\text { pericellular fibrosis } \\
\text { Pepatic fibrosis }\end{array}$ \\
$\begin{array}{l}\text { Pericentral sclerosis associated with } \\
\text { pericellular fibrosis without evidence of } \\
\text { other change }\end{array}$ \\
Liver cirrhosis & $\begin{array}{l}\text { Definite pseudonodular formation with } \\
\text { micronodular appearance }\end{array}$ \\
\hline
\end{tabular}

The subjects were divided into three groups according to the histological classification described: group I consisted of seven cases with non-specific change or fatty liver. No pericentral sclerosis or pericellular fibrosis could be seen in this group. Group II consisted of five cases with alcoholic hepatic fibrosis and alcoholic hepatitis. In this group, pericentral sclerosis associated with pericellular fibrosis were the characteristic features. Group III consisted of five cases with alcoholic liver cirrhosis.

The mean age of group III ( $54.6 \pm 2.9$ years: mean \pm SEM) was higher $(\mathrm{P}<0.05)$ than that of group II $(42.5 \pm 1.7$ years $)$. There was no significant difference, however, between the mean age of group I ( $44.6 \pm 3.8$ years) and group II. Also the difference between the mean age of group I and that of group III was not statistically significant. Duration of habitual drinking in group II $(32.6 \pm 2.4$ years $)$ was longer $(\mathrm{P}<0.05)$ than that of group I (21.4 \pm 2.5 years) and group III (21.5 \pm 4.4 years). In addition, total alcohol consumption of group III $(1740 \pm 160 \mathrm{~kg})$ was greater $(\mathrm{P}<0.01)$ than that of group I $(670 \pm 140 \mathrm{~kg})$ and group II $(630 \pm 20$ $\mathrm{kg})$. As to the mean abstinent period before ethanol administration, there were no significănt differences among the three groups.

\section{PROCEDURES}

Before ethanol administration, a standard diet was given to each patient for five days. This represented a total heat value of 2200 kilocalories and contained $100 \mathrm{~g}$ protein. After overnight fasting for 15 hours, $20 \%$ ethanol $(0.75 \mathrm{~g} / \mathrm{kg}$ of body weight $)$ was given orally for 60 minutes. Blood samples were collected from the antecubital vein before and six hours after ethanol administration. During the study, neither drinking nor eating was permitted (Table 2 ).

\section{Table 2 Procedure of oral ethanol administration}

1. Standard diet for five days $(2200 \mathrm{Cal}$ containing $100 \mathrm{~g}$ protein per day)

2. Overnight fasting (15 hours)

3. Blood sampling

4. Peroral administration of $20 \%$ ethanol for 60 minutes ( $0.75 \mathrm{~g}$ ethanol $/ \mathrm{kg}$ body weight)

5. Blood sampling (after 6 hours)

6. Measurement of serum glycoprotein levels

\section{TECHNIQUES}

Serum concentrations of total protein and albumin were measured colorimetrically by an autoanalyser (SMAC; Technicon Corp.) using biuret and bromcresol-green, respectively. Serum bilirubin concentrations were measured by the method of Jendrassik using SMAC. Serum aspartate aminotransferase (sGOT) activity was measured by the method of ultra violet assay using SMAC. Serum gamma glutamyl transpeptidase (sGGT) activity was measured by a modification of the method of Orlowski et al. ${ }^{7}$ All these parameters were assayed within two days after the blood sampling. Serum glycoproteins (prealbumin, $\alpha_{2}$ HSglycoprotein, haptoglobin, and $\alpha_{2}$ macroglobulin) were measured by single radial immunodiffusion using partigen plate (Hoechst Corp.)

\section{ALTERNATIVE RATIOS}

We calculated alternative ratios (AR), in order to take into account the degree of change in serum glycoprotein levels observed after ethanol administration as follows: $\mathrm{AR}=(\mathrm{Y}-\mathrm{X}) / \mathrm{X}$, where $\mathrm{X}$ is the serum glycoprotein level before ethanol administration and $Y$ is the serum glycoprotein level six hours after administration.

\section{STATISTICS}

Results are expressed as the mean \pm SEM. Signifcance between differences of means was assessed by Student's $t$ test and Kruskal-Wallis's $h$ test.

\section{Results}

SERUM ENZYME ACTIVITIES

Before ethanol administration, the mean activity of sGOT in group III $(67.0 \pm 17.8 \mathrm{U} / \mathrm{l})$ was higher than 
that of group I (29.0 $\pm 6 \cdot 1)$ and group II (28.5 $\pm 6 \cdot 1)$; there were, however, no significant differences between the three groups. The mean activity of sGGT was highest in group III $(116.6 \pm 34.5 \mathrm{U} / 1)$, compared with that in group I (62.1 \pm 12.8$)$ and group II (99.3 \pm 37.6$)$; there were, however, no significant differences between these three groups. Ethanol administration caused no change in sGOT and sGGT activity in any of the groups (Fig. 1).

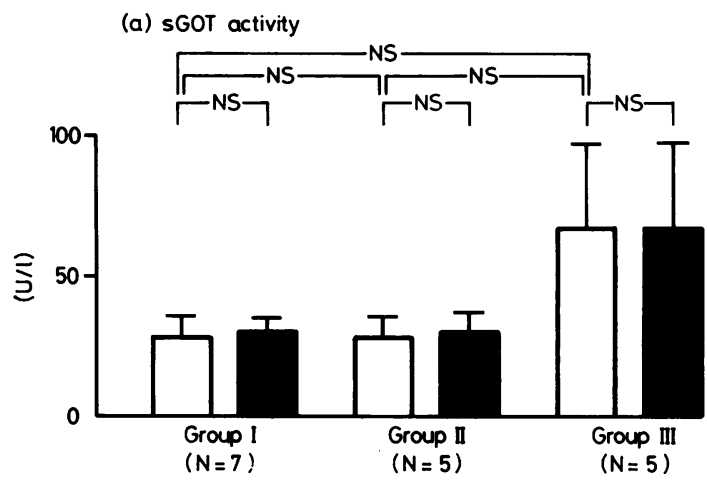

(b) $S G G T$ activity

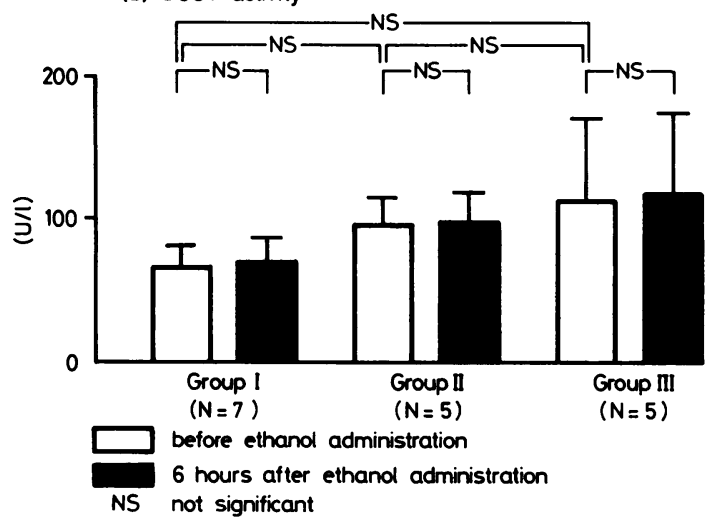

Fig. 1 Serum enzyme activities before and six hours after ethanol administration. NS: not significant. N: number of subjects. Mean $( \pm S E M)$ values for each group are shown by open and shaded bar.

SERUM PROTEIN, ALBUMIN, AND BILIRUBIN Before ethanol administration, there were no signifcant differences among the three groups in serum concentrations of protein, albumin, and bilirubin. In addition, the ethanol caused no change in serum levels of these three parameters in any of the groups (Fig. 2).

\section{SERUM GLYCOPROTEINS}

Before ethanol administration, there were no significant differences in the mean serum prealbumin levels among group I $(0.251 \pm 0.037 \mathrm{~g} / 1)(25.1 \pm 3.7$

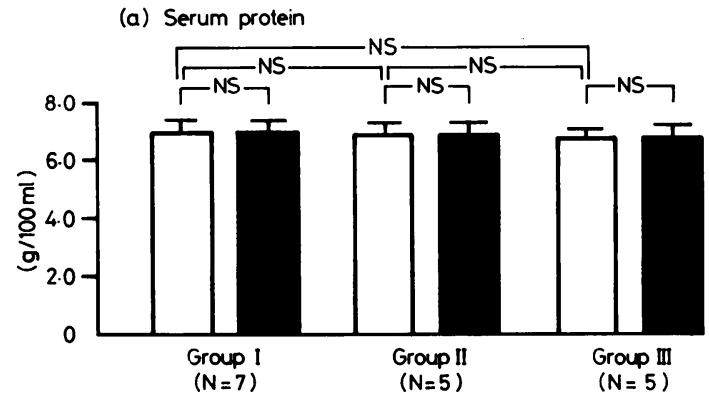

(b) Serum albumin

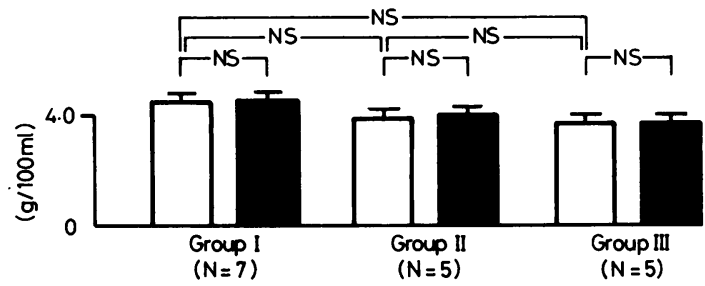

(c) Serum bilirubin

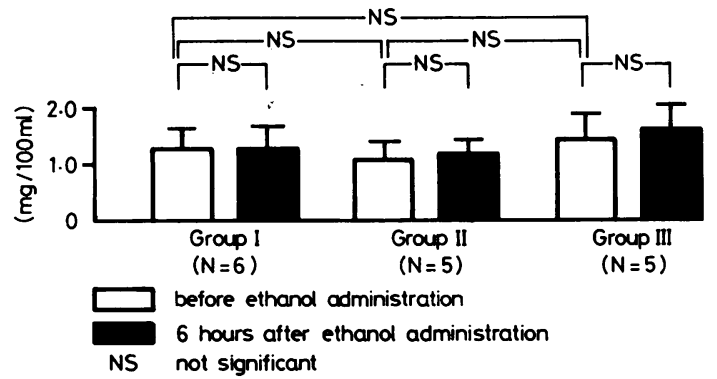

Fig. 2 Serum concentrations of protein, albumin, and bilirubin before and six hours after ethanol administration. NS: not significant. N: number of subjects. Mean ( $\pm S E M)$ values are shown. (SI conversion factor $\times 0.01$.)

$\mathrm{mg} / 100 \mathrm{ml})$, group II $(0.241 \pm 0.073 \mathrm{~g} / 1)(24.1 \pm 7.3$ $\mathrm{mg} / 100 \mathrm{ml})$ and group III $(0.185 \pm 0.032 \mathrm{~g} / 1)(18.5$ $\pm 3.2 \mathrm{mg} / 100 \mathrm{ml}$ ). After the ethanol was given, the serum prealbumin level decreased significantly $(\mathrm{P}<0.05)$ in group I $(0.251 \rightarrow 0.192 \pm 0.031 \mathrm{~g} / 1)$ $(25.1 \rightarrow 19.2 \pm 3.1 \mathrm{mg} / 100 \mathrm{ml})$. In contrast; it increased significantly $(\mathrm{P}<0.05)$ in group II $(0.241 \rightarrow$ $0.347 \pm 0.085 \mathrm{~g} / 1)(24.1 \rightarrow 34.7 \pm 8.5 \mathrm{mg} / 100 \mathrm{ml})$ and group III $(0.185 \rightarrow 0.277 \pm 0.056 \mathrm{~g} / \mathrm{l})(18.5 \rightarrow$ $27.7 \pm 5.6 \mathrm{mg} / 100 \mathrm{ml}$ ) (Fig. 3a).

$\alpha_{2} \mathrm{HSglycoprotein}$ level showed similar results to prealbumin; $\alpha$ HSglycoprotein level showed no differences among the three groups before ethanol administration. After the ethanol was given, it decreased significantly $(\mathrm{P}<0.05)$ only in group I $(0.565 \pm 0.073$ $\rightarrow 0.436 \pm 0.079 \mathrm{~g} / \mathrm{I})(56.5 \pm 7.3 \rightarrow 43.6 \pm 7.9$ $\mathrm{mg} / 100 \mathrm{ml})$, and increased significantly $(\mathrm{P}<0.05)$ in group III $(0.459 \pm 0.055 \rightarrow 0.643 \pm 0.121 \mathrm{~g} / 1)(45.9$ $\pm 5 \cdot 5 \rightarrow 64 \cdot 3 \pm 12 \cdot 1 \mathrm{mg} / 100 \mathrm{ml}$ ) (Fig. $3 \mathrm{~b}$ ). 
(a) Prealbumin

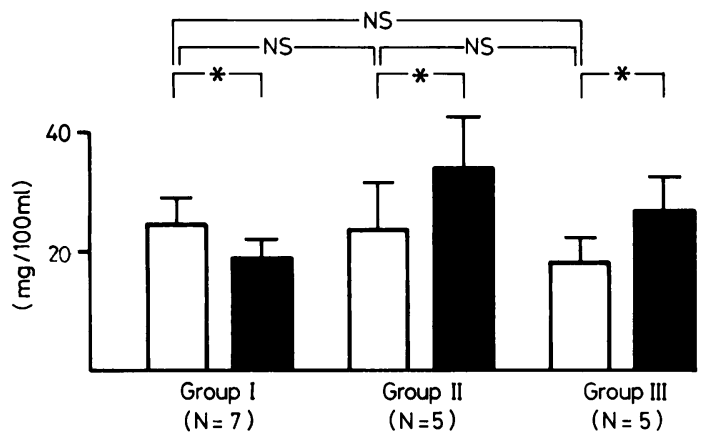

(b) $\alpha_{2} \mathrm{HS}$-glycoprotein

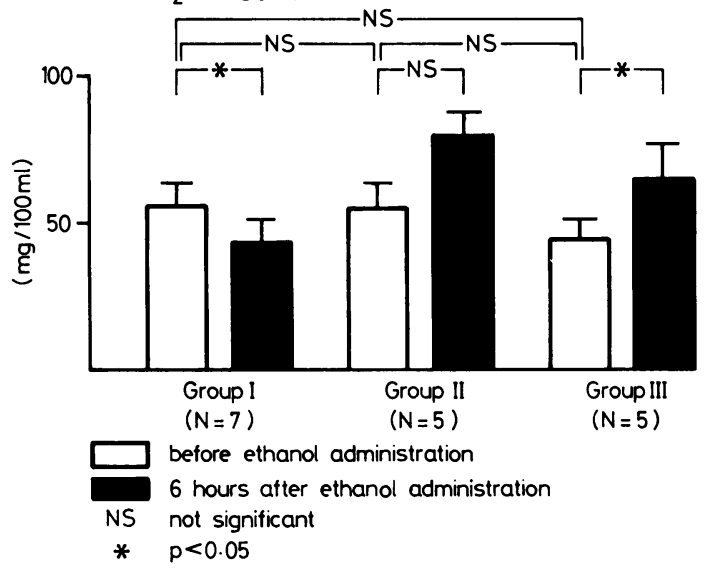

Fig. 3 Serum glycoprotein levels before and six hours after ethanol administration. NS: not significant. Mean ( \pm SEM) values are depicted. (SI conversion factor $\times 0.01$.)

The haptoglobin level of group III $(0.78 \pm 0.095$ $\mathrm{g} / \mathrm{l})(78.0 \pm 9.5 \mathrm{mg} / 100 \mathrm{ml})$ was significantly lower than that of group I $(1.794 \pm 0.288 \mathrm{~g} / 1)(179.4 \pm$ $28.8 \mathrm{mg} / 100 \mathrm{ml}$ ) even before ethanol administration. After ethanol administration, it decreased significantly only in group I $(1.794 \rightarrow 1.314 \pm 0.208 \mathrm{~g} / \mathrm{l})(179.4$ $\rightarrow 131.4 \pm 20.8 \mathrm{mg} / 100 \mathrm{ml})$. By contrast, it increased in group II $(0.574 \pm 0.076 \rightarrow 0.789 \pm 0.078 \mathrm{~g} / \mathrm{I})(57.4$ $\pm 7.6 \rightarrow 78.9 \pm 7.8 \mathrm{mg} / 100 \mathrm{ml})$ and group III $(0.780$ $\rightarrow 1.432 \pm 0.304 \mathrm{~g} / .1)(78.0 \rightarrow 143.2 \pm 30.4 \mathrm{mg} / 100$ $\mathrm{ml}$ ), but the changes were not significant (Fig. 4a).

$\alpha_{2}$ Macroglobulin level showed similar results to haptoglobin; nevertheless, the serum levels of the three groups showed no significant difference from each other. Changes on ethanol administration were not significant, either (Fig. 4b).

\section{ALTERNATIVE RATIOS}

Mean alternative ratios are shown in Fig. 5. Each glycoprotein measured showed very similar alternative (a) Haptoglobin
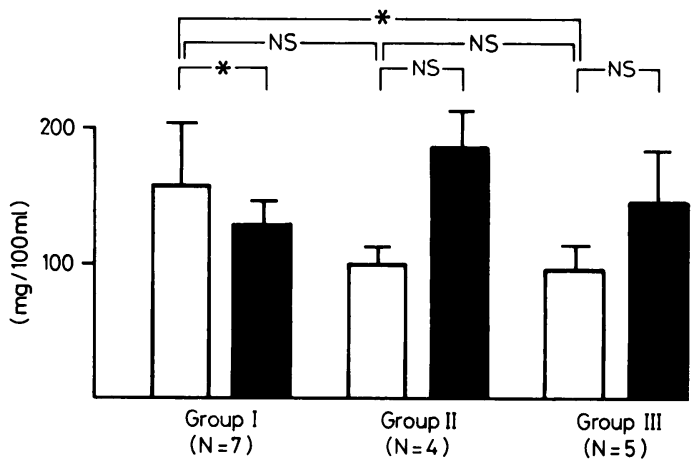

(b) $x 2^{- \text {macroglobulin }}$

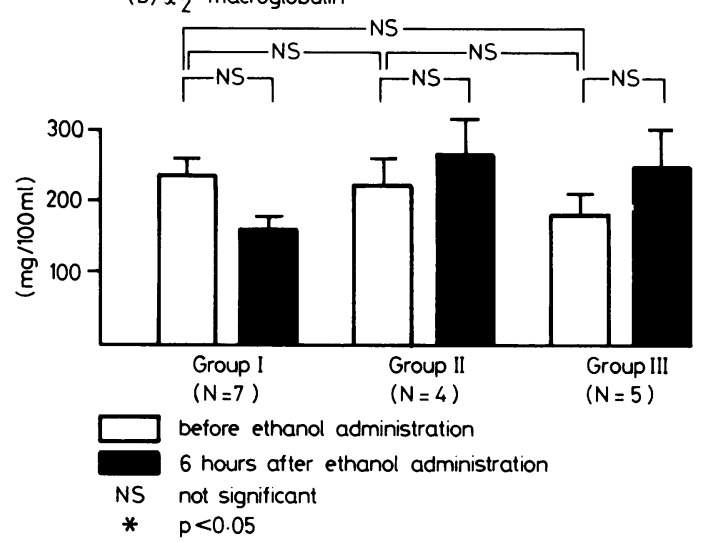

Fig. 4 Serum glycoprotein levels before and six hours after ethanol administration. Mean $( \pm S E M)$ values are depicted. (SI conversion factor $\times 0.01$.)

ratios; the mean alternative ratios of group I showed values lower than zero. In contrast, all of those in group II and group III were positive. We found apparent differences $(P<0.005)$ between the mean alternative ratio of group I and those of group II and group III, respectively.

\section{Discussion}

It is difficult to detect the presence of pericentral sclerosis associated with pericellular fibrosis, using only clinical data, without liver biopsy. Indeed, the present study showed that there was no significant difference between group I and group II, before the administration of ethanol, in terms of serum enzyme activities and serum concentrations of protein, albumin, and bilirubin. In the present study, however, the findings that serum glycoprotein levels changed on ethanol administration and that the alternative ratios were different between group I and group II have particular import- 
(a) Prealbumin

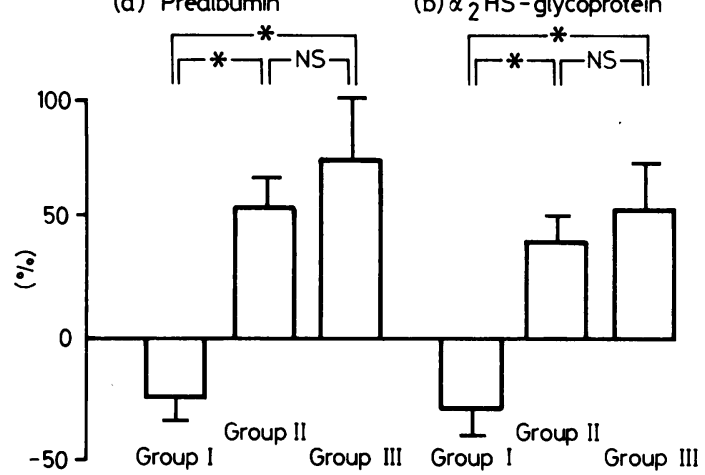

(c) Haptoglobin

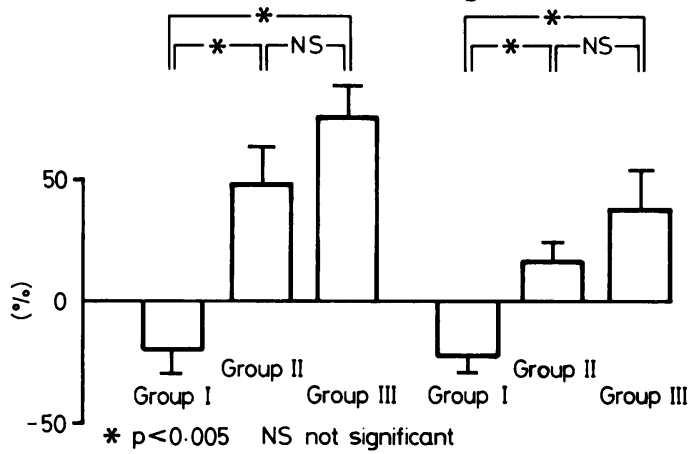

Fig. 5 Alternative ratio of serum glycoprotein in each group. Alternative ratio was calculated in each patient. Mean ( $\pm S E M)$ values are shown by open bar indicating positive or negative percentage.

ance. We suggest that the measurement of serum glycoprotein levels before and after oral ethanol administration is a useful way of discriminating between alcoholic patients with pericentral sclerosis and pericellular fibrosis and those without such lesions.

Several studies showed a significant rise in serum enzyme activity after ethanol administration in chronic alcoholics ${ }^{8}$ or even in normal subjects. ${ }^{10}$ In the present study, however, we observed no rise in serum enzyme activity in our subjects after oral ethanol administration. This discrepancy is probably due to differences in the experimental design, such as method of ethanol administration, loading dosage of ethanol, and/or abstinent time before the experiment.

Plasma proteins, with the exception of albumin and immunoglobulins, are synthesised and secreted from the liver as glycoproteins. ${ }^{11}$ It has been recognised that the turnover time of most glycoproteins is short and their pooling sizes are small. ${ }^{12}$ The changes in serum glycoprotein levels may therefore reflect the altered protein metabolism of the hepatocyte in the early stage of liver disease. Several studies indicate a diminution of serum glycoprotein in acute hepatic failure ${ }^{13}$ advanced liver cirrhosis, and other diseases. ${ }^{14}$ Other studies demonstrated that ethanol causes reduced glycoprotein synthesis ${ }^{15}$ and further impairment of secretion, ${ }^{516}$ and suggested that this change resulted in the intracellular accumulation of glycoprotein in the hepatocyte. ${ }^{6}$

The present finding that the serum glycoprotein level of group I decreases after acute ethanol administration suggests impairment of glycoprotein secretion from the hepatocyte after acute ethanol intoxication. This interpretation is in agreement with recent studies suggesting impaired glycoprotein secretion during ethanol intoxication. On the other hand, we found that serum glycoprotein levels of group II and group III increased after ethanol administration. It may be suggested that this increase of serum glycoprotein level is partly due to the increased permeability of the hepatocyte membrane, after ethanol intoxication, in the liver with advanced damage, although it is not possible to define the exact mechanism of this change from the present study.

We suggest, on the strength of the present study, that the determination of serum glycoprotein levels is useful in the differentiation of alcoholic patients with hepatic fibrosis and alcoholic hepatitis from alcoholics with fatty liver, even when liver biopsy is not available.

This study was supported in part by Grant 337029 from the Japanese Ministry of Education. The authors would like to thank Dr. Leonard B Berman for his assistance in the preparation of this manuscript.

\section{References}

1 Takeuchi J, Okudaira M, Takada A, et al. The increasing incidence of alcoholic liver disease in Japan (1969-1977). Jap J Gastroenterol 1979; 76:2178-85.

2 Van Waes L, Lieber CS. Early perivenular sclerosis in the alcoholic fatty liver: an index of progressive liver injury. Gastroenterology 1977; 73:646-50.

3 Baraona E, Leo MA, Borowsky SA, et al. Alcoholic hepatomegaly: accumulation of protein in the liver. Science 1975; 190:794-5.

4 Leevy CM. Fatty liver: a study of 270 patients with biopsy proven fatty liver and a review of the literature. Medicine 1962; 41:249-76.

5 Sorrell MF, Tuma DJ. Selective impairment of glycoprotein metabolism by ethanol and acetaldehyde in rat liver slices. Gastroenterology 1978; 75:200-5.

6 Baraona E, Leo MA, Borowsky SA, et al. Pathogenesis of alcohol-induced accumulation of protein in the liver. $J$ Clin Invest 1977; 60:546-54.

7 Orlowski M, Meister A. $\gamma$-Glutamyl-p-nitroanilide: a new convenient substrate for determination and study of L- and D- $\gamma$-glutamyltranspeptidase activities. Biochim Biophys Acta 1963; 73:679-81. 
8 Nishimura M, Hasumura Y, Takeuchi J. Effect of an intravenous infusion of ethanol on serum enzyme and lipids in patients with alcoholic liver disease. Gastroenterology 1980; 78:691-5.

9 Bang UN, Iversen K, Jagt T. Serum glutamic oxaloacetic transaminase activity in acute and chronic alcoholism. JAMA 1958; 168:156-60.

10 Goldberg DM, Watts C. Serum enzyme changes as evidence of liver reaction to oral alcohol. Gastroenterology 1965; 49:256-61.

11 Sorrell MF, Tuma DJ. Effects of alcohol on hepatic metabolism: selected aspects. Clin Sci 1979; 57:481-9.

12 Winzler RJ. Metabolism of glycoproteins. Clin Chem $1965 ; 11: 339-47$.
13 Kobayashi K, Kameda S, Sugimoto T, et al. A clinicopathological study of acute hepatitis: The measurement of serum proteins with rapid turnover for early diagnosis of fatal hepatitis. Acta Hepatol Jpn 1977; 18:79-84.

14 Murray-Lyon IM, Minchin CHG, et al. Quantitative immunoelectrophoresis of serum proteins in cryptogenic cirrhosis, alcoholic cirrhosis and active chronic hepatitis. Clin Chim Acta 1972; 39:215-21.

15 Mookerjea S, Chow A. Impairment of glycoprotein synthesis in acute ethanol intoxication in rats. Biochim Biophys Acta 1969; 184:83-92.

16 Sorrell MF, Tuma DJ, Barak AJ. Evidence that acetáldehyde irreversibly impairs glycoprotein metabolism in liver slices. Gastroenterology 1977; 73:1138-41. 